6. Gaal S, Hartman C, Giesen P, van Weel C, Verstappen W, Wensing M. Complaints against family physicians submitted to disciplinary tribunals in the Netherlands: lessons for patient safety. Ann Fam Med. 2011;9(6):522-527

7. Saxe JS. Promoting healthy lifestyles and decreasing childhood obesity: increasing physician effectiveness through advocacy. Ann Fam Med. 2011;9(6):546-548.

8. Solberg LI, Asche SE, Fontaine P, Flottemesch TJ, Anderson LH. Trends in quality during medical home transformation. Ann Fam Med. 2011;9(6):515-521.

9. Eaton CB, Parker DR, Borkan J, et al. Translating cholesterol guidelines into primary care practice: a multimodal cluster randomized trial. Ann Fam Med. 2011;9(6):528-537.
10. Ridd MJ, Lewis G, Peters TJ, Salisbury C. The Patient-Doctor Depthof-Relationship Scale: development and validation. Ann Fam Med. 2011;9(6):538-545.

11. Kjeldmand D, Holmström I. Balint groups as a means to increase job satisfaction and prevent burnout among general practitioners. Ann Fam Med. 2008;6(2):138-145

12. Annals Journal Club: Balint groups and 'the joy of being a doctor.' Ann Fam Med. 2008;6(2):iii.

13. Shorer $Y$, Biderman A, Levi A, et al. Family physicians leaving their clinic-the Balint group as an opportunity to say good-bye. Ann Fam Med. 2011;9(6):549-551.

\title{
EDITORIAL
}

\section{Where the United States Falls Down and How We Might Stand Up}

\author{
Robert L. Pbillips, Jr, MD, MSPH
}

The Robert Graham Center, Washington, DC

Ann Fam Med 2011;9:483-485. doi:10.1370/afm.1331.

$\mathrm{T}$ he Commonwealth Fund and Rand Europe announced this week that the United States ranks last among developed countries in "mortality amenable to health care" that are considered preventable with timely and effective health care. Preventable death rates declined during the last decade, but the rate of improvement in the United States was slower compared with other countries such that we continue to fall further behind. Compared with other countries, the United States also has much wider disparities in health status and outcomes.

A study by Banks, Marmot, and Oldfield showed that, by most measures, people in the highest one-third of income in the United States have outcomes similar to those in the lowest one-third in the United King-

Conflicts of interest: author reports none.

\section{CORRESPONDING AUTHOR}

Robert L. Phillips, Jr, MD, MSPH

The Robert Graham Center

1350 Connecticut NW, Suite 201

Washington, DC 20036

bphillips@aafp.org $\mathrm{dom}^{2}$ - the rich in the United States, having unfettered access to expensive, high-tech, but fragmented and depersonalized care, are not better off than the poor in a country that has a comprehensive system for providing access to integrated, personalized, prioritized care. One of the authors of that study, Sir Michael Marmot, said that same year, "There is no question that part of improving health in poorer countries, as in richer, is the provision of comprehensive primary care.." ${ }^{13}$ This lack of an integrative and robust primary care function is one of the ways we fall down as a country.

A second major failing is that the United States does not provide sufficient access to timely care for a large swath of its population. Access typically means removing or reducing financial hurdles, often as insurance, and having a person with whom people can form sustained, healing relationships.

The third major area where we fall down compared with other countries is in our capacity to monitor and take responsibility for the health of communities and populations. A functional health care system benefits from systems focused both on the health of individuals and of communities of people and the whole populace.

There are certainly other contributors, but these 3 likely explain why we continue to fall down and fall further behind. 
Three articles in this issue of the Annals highlight these problems. The first article, by DeVoe et al, shows the resulting barriers to care that occur for children when parents do not have a usual source of care (USC). ${ }^{4}$ Another, by Mainous et al, reveals that the uninsured are discharged sooner than insured people, particularly from for-profit hospitals. ${ }^{5}$ And a third, by Odom Walker et al, looks at the effects of closure of a county safety-net hospital on access to timely care for underserved communities. ${ }^{6}$

The study by DeVoe et al connects the importance of parent-child concordance for having a USC to receipt of appropriate health care. They find that nearly 1 in 10 (9\%) children have no USC, and nearly 1 in 5 (18\%) parents have no USC. The authors focus on the $12.4 \%$ of children who have a USC but neither parent has a USC to study whether parental status affects the child's health care patterns. As the authors point out, prior studies have shown that insured children of uninsured parents are at higher risk of not receiving appropriate care, and children without a stable USC are similarly likely to have gaps in care. ${ }^{7,8}$ Hispanic children were particularly more likely to not have a USC and to have one or more parents without a USC, as were children whose health insurance coverage was unstable. The study reiterates past findings that children without a USC experience unmet health needs, but it also finds that parental USC status is independently associated with their child's receipt of care. Children of low-income, near-poor, and impoverished families were more than twice as likely to experience unmet medical or prescription needs compared with those in highincome families. Even middle-income children were nearly twice as likely to not get needed care. Children who had a USC but whose parents did not were more similar to those without a USC in their risk of having unmet health needs, but they were more likely to have had a doctor visit in the past year. If a child with no USC had a parent with no USC, the risk of having unmet health needs were worse by several measures than if their parent(s) did have a USC. These findings add to the evidence that insurance coverage and access to health care relationships are a family matter.

The study by Mainous et al finds a disturbing difference in length of hospital stay for uninsured patients when compared with patients having any insurance, but particularly when compared with patients covered by Medicaid. Controlling for patient characteristics and comorbidities increased these differences. Reduced length of stay was significant in for-profit hospitals but not for government hospitals. Length of stay for selfpaying patients was shorter in for-profit hospitals than in government and nonprofit hospitals, and longer for patients with insurance other than Medicaid than for patients in government hospitals. The authors took the important step of excluding from the analysis patients who leave against medical advice.

That uninsured patients were more than 3 times as likely to leave against medical advice suggests uninsured patients may feel increased pressure to leave early_-perhaps because of health care debt, need to work, lack of child care, fear-but the concern in these findings is that hospitals may have an increased incentive to release these patients earlier to reduce their own costs of uncompensated care. This difference in length of stay was less but also significant in government and nonprofit hospitals, which may also have financial incentives for earlier discharge.

There appears to be no difference in in-hospital mortality for uninsured and insured patients, which is important, particularly because it is born of a large, nationally representative database of hospital discharges. Previous studies of limited geography or disease focus suggested that uninsured patients might be more likely to die. Although this latter finding is important, the implication that hospitals may treat patients differently based on insurance status, particularly for-profit hospitals, and the lack of ability to assess out-of-hospital mortality or other outcomes of early discharge are very troubling.

This issue also features a study by Odom Walker et al that qualitatively explores the perspective of community-based primary care physicians regarding the closure of Martin Luther King (MLK) Hospital, a county-operated hospital in South Los Angeles. They sought the perspectives of both safety-net and private practice physicians located within and beyond the estimated service area of MLK. They found that the closure reduced access to specialty care, produced overcrowding of other area hospitals and emergency departments, disrupted and delayed care, reduced communication and patient connections to primary care practices, and led to a loss of community primary care physicians as a result of physician departure and loss of MLK's training programs. The impact, which was greatest within the MLK service area, was experienced beyond it as well. The authors suggest that it is important to consult primary care physicians before closure of safety-net hospitals to try to reduce the community impact. For me, it speaks to the unintended consequences that happen when we do not have the mind-set of community accountability. If MLK had an identified service area and was monitoring the health and utilization patterns of its community, these factors might have been considered in how closure of this hospital would affect that community.

The Patient Protection and Affordable Care Act (ACA) has important provisions that may help the 
United States move toward the health outcomes of the rest of the developed world by taking on the problems exemplified in these 3 studies. To the problem of closure of a major safety-net hospital in Los Angeles, the ACA requires that nonprofit hospitals assess their community and develop interventions based on that assessment every 3 years ( $\$ 9007)$. It is a start toward defining community and creating accountability for that community's health and well-being. This provision may also help with the early discharge of uninsured patients, particularly if hospitals must take account of the out-of-hospital outcomes associated with such practices. Of course, the ACA provisions for insurance expansion, through Medicaid (§1331, §1413, §2001\$2501), employment-based insurance (\$1511-§1515), and insurance exchanges (\$1311) may reduce the incentives (for hospitals and patients) for early discharge. The ACA enhances focus on population health in several ways that are well intentioned but that are at some risk of not being well coordinated. It expands experiments with the patient-centered medical home (§3021, §5301) and accountable care organizations (§3022). The law also creates demonstrations of community health teams $(\$ 3502)$, supports community transformation grants (\$4201), and creates efforts to link primary care and public health (\$3012). The ACA's impact on having a USC will be helped not only by insurance coverage expansion but also by its proposed doubling of community health center capacity ( $\$ 5601)$, more than two-fold expansion of the National Health Service Corps (\$5207), and its small but meaningful promotions of primary care.

The ACA is far from perfect, but it may help the Unites States stand up from its stumbles by taking on these 3 important problems, namely, by building more robust and comprehensive models of primary care. Recent estimates show inputs into primary care at 3\% to $6 \%$ of total health care spending compared with more than $10 \%$ in most other developed countries. ${ }^{9}$ The current model is starved for resources and forced to function strictly on fee-for-service. There are good examples of robust primary care-based systems in the United States, in such places as Geisinger Health System, that more than recoup the cost put into them and with better outcomes. There are many reasons to support providing health access for all, but the burning political reason is to get people in to timely health care to avoid much higher costs once they reach Medicare eligibility. With the same policy, we can also do what is morally and fiscally right. Finally, we are the last developed country, quickly being passed by developing countries, in taking a population view of health. Without it, clinicians do not know who is taking their medi- cations, which patients have not followed up for chronic care visits or preventive services, or where whole neighborhoods are suffering poor health outcomes despite conventional approaches to care. Primary care clinicians cannot afford to lose the personal view that we and our patients enjoy now, but we literally cannot afford the unidentified costs and suffering that the strictly personal approach to care currently produces. The capacity to take the larger view of our patient populations and our communities is key to taking ownership, developing our clinical and community responses, and monitoring our progress. It is truly the only way we will stand up on reducing disparities in health.

Primary care researchers, as have the research teams featured in this issue of Annals, will help us know whether we are doing better. Primary care health services researchers are too few in number for the tremendous job of showing us where we fall down.

To read or post commentaries in response to this article, see it online at http:/lwww.annfammed.org/content/9/6/483.

Key words: Health policy; access to health care; primary health care; delivery of health care

Submitted October 7, 2011; submitted, revised, October 7, 2011; accepted October 7, 2011.

Disclaimer: The information and opinions contained in research from the Graham Center do not necessarily reflect the views or policy of the AAFP.

\section{References}

1. Nolte $\mathrm{E}, \mathrm{McKee} \mathrm{M}$. Variations in amenable mortality-trends in 16 high-income nations. Health Pol. [In press corrected proof]. http:// www.sciencedirect.com/science/article/pii/S016885101100159X. Accessed Sep 27, 2011.

2. Banks J, Marmot M, Oldfield Z. Disease and disadvantage in the United States and England. JAMA. 2006;295(17):2037-2045.

3. Marmot M. Harvareian oration: health in an unequal world. Lancet. 2006;368:2081-2094.

4. DeVoe JE, Tillotson CJ, Wallace LS, Angier H, Carlson MJ, Gold R. Parent and child usual source of care and children's receipt of health care services. Ann Fam Med. 2011;9(6):504-514.

5. Mainous AG III, Diaz VA, Everett CJ, Knoll ME. Impact of insurance and hospital ownership on hospital length of stay among patients with ambulatory care-sensitive conditions. Ann Fam Med. 2011;9(6):489-495.

6. Odom Walker K, Clarke R, Ryan G, Brown AF. The effect of closure of a local safety-net hospital on primary care physicians' perceptions of their role in patient care. Ann Fam Med. 2011;9(6):496-504.

7. DeVoe JE, Tillotson C, Wallace LS. Children's receipt of health care services and family health insurance patterns. Ann Fam Med. 2009;7(5):406-413.

8. DeVoe J, Saultz J, Tillotson C, Krois L. A medical home versus temporary housing: the importance of a stable usual source of care among low-income children. Pediatrics. 2009;124(5):1363-1371.

9. Goroll AH, Berenson RA, Schoenbaum SC, Gardner LB. Fundamental reform of payment for adult primary care: comprehensive payment for comprehensive care. J Gen Intern Med. 2007;22:410-415. 